\title{
EDUCAÇÃO ESPECIAL E SAÚDE MENTAL INFANTOJUVENIL: inclusão e seus descaminhos
}

\author{
ROSÂNGELA DA LUZ MATOS \\ Psicóloga (PUCRS). Mestre em Psicologia Social e Institucional (UFRGS), Doutora em \\ Sociologia (UFC). Pós-doutorado Estudos Interdisciplinares sobre Universidade (UFBA). Líder \\ do Grupo de Pesquisa Educação, Universidade e Região (EdUReg). ORCID: https://orcid. \\ org/0000-0001-7764-9121 E-mail: rosangeladaluzmatos@gmail.com
}

\section{NATALY FARIAS DE GOES}

Pedagoga (UFBA). Mestranda no Programa de Pós-Graduação Gestão e Tecnologias Aplicadas a Educação (GESTEC), Universidade do Estado da Bahia (UNEB). Membro do Grupo de Pesquisa Educação, Universidade e Região (EdUReg). ORCID: https://orcid.org/0000-00022944-9798 E-mail: nathygoes@hotmail.com 


\section{RESUMO}

Este artigo integra uma pesquisa desenvolvida no Programa de Pós-Graduação Gestão e Tecnologias Aplicadas a Educação (GESTEC), na Universidade do Estado da Bahia (UNEB), e tem como objetivo analisar a inclusão e seus descaminhos através da Política Nacional de Educação Especial na perspectiva da Educação Inclusiva, das Conferências da Organização das Nações Unidas para a Educação, a Ciência e a Cultura (UNESCO) e dos regramentos da política de saúde mental infantojuvenil brasileira. O procedimento para a produção dos dados observou natureza analítica, com abordagem qualitativa e pesquisa documental. As fontes de informação foram os regramentos legais da política nacional e internacional acessados em sites oficiais do Ministério da Educação, Ministério da Saúde, Conselho Nacional de Saúde e UNESCO. As conclusões indicam que, desde meados do século XX, o Banco Mundial exerce forte influência para o delineamento dos regramentos legais da educação especial no Brasil, e as políticas de educação especial e da saúde mental encontram diálogo na articulação intersetorial como caminho de implementação das políticas públicas em prol do direito de crianças e adolescentes.

Palavras-chave: Educação especial. Educação inclusiva. Políticas públicas. Saúde mental.

\section{SPECIAL EDUCATION AND CHILDREN'S MENTAL HEALTH: Inclusion and its misplaced ${ }^{1}$}

${ }^{1}$ The misplaced term is used to refer to the instability of the paths of inclusive education.

This article derives of a research developed in the PostGraduate Program in Management and Applied Technologies for Education (GESTEC), at the State University of Bahia (UNEB), and aims to analyze inclusion and its misplaced through the National Policy on Special Education in the perspective of Inclusive Education, of the Conferences of the United Nations Educational, Scientific and Cultural Organization (UNESCO) and of the rules of Brazilian child and youth mental health policy. The procedure for producing the data was analytical in nature, with a qualitative approach and documental research. The sources of information were the legal regulations of national and international policy accessed on official websites of the Ministry of Education, Ministry of Health, National Health Council and UNESCO. Conclusions indicate that since the mid-twentieth century, the World Bank exerts a strong influence on the design of legal regulations for special education in Brazil, and special education and mental health policies find dialogue in the intersectoral articulation as a way of implementing policies the rights of children and adolescents.

Keywords: Special education. Inclusive education. Public policy. Mental health.

\section{EDUCACIÓN ESPECIAL Y SALUD MENTAL INFANTOJUVENIL: Inclusión y sus descaminos}

Este artículo se deriva de una investigación desarrollada en el Programa de Postgrado Gestión y Tecnologías Aplicadas a la Educación (GESTEC), en la Universidad del Estado de Bahía (UNEB), y tiene como objetivo analizar la inclusión y sus descaminos a través de la Política Nacional de Educación Especial en

plulais Salvador, v. 3, n.3 , p. 12-37, set./dez. 2018 
la perspectiva de la Educación Inclusiva, de las Conferencias de la Organización de las Naciones Unidas para la Educación, la Ciencia y la Cultura (UNESCO) y los reglamentos de la política de salud mental infantojuvenil brasileña. El procedimiento para la producción de los datos observó naturaleza analítica, con abordaje cualitativo e investigación documental. Las fuentes de información fueron las reglas legales de la política nacional e internacional accedidas en sitios oficiales del Ministerio de Educación, Ministerio de Salud, Consejo Nacional de Salud y UNESCO. Las conclusiones indican que, desde mediados del siglo XX, el Banco Mundial ejerce una fuerte influencia para el delineamiento de los reglamentos legales de la educación especial en Brasil, y las políticas de educación especial y de la salud mental encuentran diálogo en la articulación intersectorial como camino de implementación de las políticas públicas en favor del derecho de niños y adolescentes.

Palabras claves: Educación especial. Educación inclusiva. Políticas públicas. Salud mental.

$\begin{array}{lccccr}\text { EDUCAÇÃO } & \text { ESPECIAL } & \text { E } & & \text { SAÚDE } & \text { MENTAL } \\ \text { INFANTOJUVENIL: } & \text { Inclusão } & \text { e } & \text { seus } & \text { descaminhos }\end{array}$

\section{Introdução}

Neste texto busca-se discutir a inclusão de crianças e adolescentes com necessidades de cuidado em saúde mental ${ }^{2}$, tendo por referência a Política Nacional de Educação Especial na Perspectiva da Educação Inclusiva, as Conferências da Organização das Nações Unidas para a Educação, a Ciência e a Cultura (UNESCO) que tratam da inclusão e os regramentos da política de saúde mental infantojuvenil brasileira.

O estudo tem natureza analítica com abordagem qualitativa. O procedimento de produção dos dados observou a pesquisa documental, já que tem como principal fonte regramentos legais da política nacional e os marcos internacionais da UNESCO para a inclusão escolar. Os Documentos objeto de análise são de domínio público e seu acesso se deu no período de janeiro a julho de 2018,

\footnotetext{
${ }^{2}$ Para nos referir a esse grupo, faremos uso do termo crianças e adolescentes usuárias de saúde mental, a partir do reconhecimento da existência de crianças e adolescentes que, por fatores diversos, encontram-se em algum momento da vida, em experiência de sofrimento psíquico, transtorno mental, ou outro estado psicossocial que demande cuidados em saúde mental. Portanto, assumimos assim, a opção por apresentálas na lógica do uso do direito ao cuidado em saúde mental.
} 
através dos sites oficiais do Ministério da Educação, Ministério da Saúde, Conselho Nacional de Saúde e UNESCO, respectivamente.

Para Lakatos e Marconi (2003, p. 175), o que caracteriza uma pesquisa documental "é que a fonte de coleta de dados está restrita a documentos, escritos, ou não.", sejam documentos de arquivos públicos ou privados, entre eles, documentos oficiais, como leis, ofícios e relatórios. Ludke e André (2015, p. 45) concordam que "estes incluem desde leis e regulamentos, normas, pareceres, memorandos [...]". Sobre as vantagens da análise documental as autoras apontam o fato de que "os documentos constituem uma fonte estável e rica, constituem também uma fonte poderosa de onde podem ser retiradas evidências que fundamentem afirmações e declarações do pesquisador." (LUDKE e ANDRÉ, 2015, p. 45).

A problematização da inclusão da população infantojuvenil com necessidades de saúde mental no sistema educacional brasileiro nos revela os descaminhos a que a inclusão foi conduzida na experiência brasileira recente. O debate é apresentado a partir de três movimentos analíticos. Um que chamamos Dissensos da universalização da educação básica, no qual demonstramos as interferências dos marcos internacionais no campo da educação inclusiva no Brasil e cuja principal consequência tem sido medidas que excluem, enquanto buscam incluir. O segundo, Ambiguidades e hibridismos conceituais da educação especial e da educação inclusiva, que demonstra que esses conceitos foram apropriados dos marcos internacionais de forma tal que os regramentos legais não comunicam a necessária especificidade desses conceitos para a definição de políticas públicas que garantam a inclusão ao longo da educação básica. O último movimento evidencia que a Politica Nacional de Educação Especial na Perspectiva da Educação Inclusiva ${ }^{3}$ (BRASIL, 2008), especifica um público alvo para a inclusão, mas deixa a descoberto os demais grupos populacionais que apresentam condições específicas que interferem no processo de aprendizagem e, por este motivo, necessitam ser contemplados pela Política. É o caso da população infantojuvenil usuária de saúde mental, e, por este motivo, o último subtítulo é chamado de Descaminhos da inclusão para a população infantojuvenil usuária de saúde mental.

Na legislação brasileira, o movimento da inclusão encontra base legal na Constituição Federal de 1988 e na Lei de Diretrizes e Bases da Educação Nacional (LDB) 9.394 de 1996. As políticas educacionais que apoiam a educação inclusiva, principalmente a partir dos anos 2000, ganham força com a definição de políticas específicas e regramentos oficiais do Ministério da Educação, a saber, a Política Nacional de Educação Especial na Perspectiva da Educação Inclusiva, implantada a partir de 2008 .

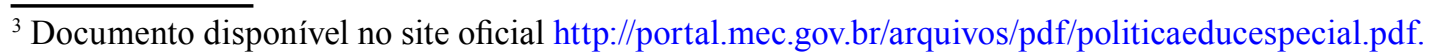


Não se nega que a defesa da universalização da educação básica, presente nas conferências da UNESCO, tem papel importante no cenário brasileiro, com destaque para a Conferência Mundial de Educação para Todos (1990), Declaração de Nova Delhi em (1993), a Conferência Mundial sobre Necessidades Educacionais Especiais (1994), o Marco da Ação de Dakar (2000) e a Convenção Internacional sobre os Direitos das Pessoas com Deficiência (2007).

Da Conferência Mundial de Educação para Todos que aconteceu em Jomtien em 1990, resultou a Declaração Mundial sobre Educação para Todos (UNESCO, 1990). Esta traz em seu artigo $3^{\circ}, \S 1^{\circ}$ a defesa da universalização da educação com qualidade para todas as crianças, os jovens e adultos. Afirma, também, que é preciso dar atenção especial às necessidades básicas de aprendizagem das pessoas com deficiência, tomando medidas que garantam igualdade de acesso à educação, segundo o artigo $3^{\circ}, \S 5^{\circ}$. Com a influência deste, e de outros marcos, no Brasil, a LDB 9.394/96 e o Plano Nacional de Educação (PNE), Lei n ${ }^{\circ}$ 10.172/2001, defendem a construção de uma escola inclusiva que garanta o atendimento à diversidade humana.

No momento atual, se evidencia forte presença do movimento da educação inclusiva no cenário brasileiro, incluindo aí o planejamento educacional. O atual Plano Nacional de Educação, Lei $\mathrm{n}^{\mathrm{o}} 13.005$ de 25 de junho de 2014, traz em seu artigo $8^{\circ}$ no $\S 1^{\circ}$ que os entes federados estabelecerão nos respectivos planos de educação estratégias que garantam, entre outras, o atendimento das necessidades, específicas, na Educação Especial, assegurando o Sistema Educacional Inclusivo em todos os níveis, etapas e modalidades. (BRASIL, 2014) O que quer dizer que os estados e os municípios brasileiros deverão garantir, em seus planos decenais, a política de educação especial de modo a constituir redes e sistemas inclusivos.

Segundo a Política Nacional de Educação Especial na Perspectiva da Educação Inclusiva (BRASIL, 2008), considera-se público alvo da educação especial os estudantes com deficiência, transtornos globais do desenvolvimento e altas habilidades/superdotação. Esta objetiva o acesso, a participação e a aprendizagem destes estudantes nas escolas regulares, e orienta os sistemas de ensino para promover respostas às necessidades educacionais.

É fato que as políticas para a educação inclusiva, no Brasil, surgem no bojo do movimento pela redemocratização da educação e pelo fortalecimento do planejamento educacional. Ainda que considerada enquanto paradigma educacional, esta não dispensa olhares atentos às suas nuances. No caso deste estudo, se quer dar ênfase a educação especial e, mais precisamente, a inclusão de crianças e adolescentes usuárias de saúde mental. 


\section{Dissensos da Universalização da Educação Básica}

Segundo Jannuzzi (2004), em 1950 iniciaram-se os movimentos comunitários que resultaram na criação das escolas especiais privadas filantrópicas para os que sempre estiveram excluídos das escolas comuns. Fomentava-se aí a concepção de educação especial com o objetivo de reunir os diferentes. De acordo com Portela (2014, p. 74),

Em meados do século XX, surgem as associações de pais de pessoas com deficiência físicas e mentais na Europa e nos Estados Unidos da América, enquanto no Brasil são criadas as Instituições Pestalozzi e as Associações de Pais e Amigos dos Excepcionais (APAE) que se destinavam à implantação de programas de reabilitação e educação especial. Nesse mesmo período, com o avanço científico, as causas e as origens das deficiências, que antes eram consideradas como visão mítica e maniqueísta entre o bem e o mal, passam a ser investigadas e consideradas do ponto de vista médico como doenças de caráter hereditário, males físicos ou mentais.

No Brasil, na década de 70 se percebe uma preocupação do poder público com essa questão. (MENDES, 2006) Quando em 1973, o Ministério da Educação cria o Centro Nacional de Educação Especial (CENESP), ainda sob o olhar integracionista, impulsionando ações educacionais direcionadas às pessoas com deficiência e superdotação, contudo, tais ações ainda eram baseadas em campanhas assistenciais e iniciativas isoladas do Estado (BRASIL, 2008).

Mundialmente, o movimento da educação inclusiva teve início no final da década de 1970, fortaleceu-se a partir de 1980 e foi ampliado no início de 1990. De acordo com Mendes (2006), naquele momento, o movimento da educação inclusiva no Brasil seguia um ritmo do contexto histórico mundial, e mais intensamente, dos Estados Unidos, que fortalecia os ideais do movimento. Sanches e Oliveira (2011) confirmam que essa ampliação ganhou força por meio da Declaração Mundial sobre a Educação para Todos (UNESCO, 1990), e firmou-se com a Declaração de Salamanca e Enquadramento da Ação na área das Necessidades Educativas Especiais em junho de 1994.

Quanto ao enfoque conceitual observam-se compreensões de inclusão conflitantes. Por exemplo, ainda se vê em debates a concepção de inclusão que atribui sua efetivação à garantia do atendimento educacional aos alunos com deficiência nas escolas regulares. O que parece diferir

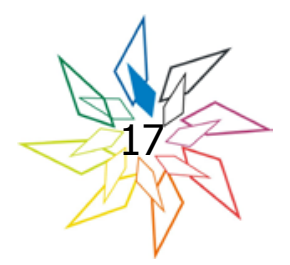


do que propõe os marcos internacionais. De maneira geral, nesses Documentos, a educação inclusiva é vista como um movimento de reforma capaz de responder à diversidade entre todos os estudantes. Isso significa reconhecer e considerar a heterogeneidade entre os sujeitos e, principalmente, efetivar um processo educativo que atenda ao que é comum a todos e ao que é específico de cada um.

Veiga-Neto e Lopes (2007, p. 10), por sua vez, problematizam as políticas de inclusão retomando o debate sobre a naturalização da norma. Eles nos dizem que "além de ser instituída no, e a partir do, próprio grupo ao qual se refere, a norma é primária e fundamentalmente prescritiva". O que os autores estão a assinalar é que a norma funciona como um mecanismo natural, portanto entendido como necessário, autorizado a pôr em movimento uma ética do ordenamento, qual seja aproximar, comparar, classificar e distinguir especificidades que serão alvo de uma ação pedagógica, médica, psicológica ou outra.

Além desse aspecto, Veiga-Neto e Lopes (2007) alertam que as políticas de inclusão escolar são, também, manifestações da ação do Estado em busca da governamentalidade ${ }^{4}$. Na governamentalidade, o Estado volta-se para as populações acionando variados mecanismos mobilizadores do exercício do poder sobre os indivíduos e os coletivos, com vistas a dirigir suas condutas em favor de uma dada política de Estado. Nas palavras dos autores

No caso das políticas de inclusão escolar, é fácil ver que a intervenção do Estado é bem maior do que costuma acontecer quando este promove campanhas públicas, mesmo que estas se utilizem da escola como ambiente de aplicação e propagação. As campanhas públicas funcionam como pedagogias culturais e, por isso, buscam o governamento sobretudo pelo discurso; elas pretendem ensinar o melhor comportamento e o que é melhor ou mais correto fazer, usar etc. [...] Já as políticas de

\footnotetext{
${ }^{4}$ Governamentalidade consiste num conceito proposto por Michel Foucault para discutir as mutações no exercício do poder de Estado entre os séculos XVII e XIX. O autor explica o conceito dizendo que, no caso da governamentalidade, o Estado apoia-se em um (ou mais) saber (res) com vistas a produz discursos em favor de uma biopolítica. Ou seja, conduzir as ações humanas em favor da preservação da própria vida. E, para exercer com eficácia o poder, mobiliza mecanismos sofisticados, também chamados dispositivos, cuja função é mobilizar as condutas humanas individual e coletivamente em favor de uma dada política, o que também é chamado de biopoder. Para conhecer este debate sugere-se: FOUCAULT, Michel. Segurança, Território, População. SP: Martins Fontes, 2008.
} 
inclusão, mesmo que se propaguem discursivamente e mesmo que se apoiem em pedagogias culturais - pois, afinal, sempre é preciso ensinar e convencer a população... -, procuram se efetivar de modo material, isto é, elas só se realizarão plenamente se e quando todos os corpos - pensados como normais e anormais - forem colocados juntos, num mesmo espaço. [...] Quando se fala em mobilização e em "sob o mesmo teto", está-se referindo tanto a um espaço físico - seja ele stricto sensu institucional (escola, empresa etc.), familiar etc. - quanto a espaços simbólicos - cultura, identidade, classificação diagnóstica..." (VEIGANETO; LOPES, 2007, p. 12)

Como se vê, os autores nos alertam que a inclusão é um tema que leva o Estado a lançar mão de expedientes que garantam "efetivar de modo material" a política de inclusão, o que não faz noutros campos da vida social. Para os autores este é um aspecto central no debate da inclusão no Brasil, pois “... o mesmo espaço considerado de inclusão - escola, empresa - pode ser considerado um espaço de exclusão. Conclui-se assim que a igualdade de acesso não garante a inclusão e, na mesma medida, não afasta a sombra da exclusão". (VEIGA-NETO; LOPES, 2007, p. 12)

Mantoan (2003) em suas análises nos diz que a inclusão é um conceito revolucionário e ele está a serviço de remover barreiras impostas pela exclusão, em seu sentido mais pleno. O desafio da inclusão para os profissionais que estão a serviço da melhoria da qualidade de vida humana é projetar artefatos e lançar propostas que não se destinam apenas a um grupo restrito. Mas alerta, nossa ação pode produzir exclusão, em busca de realizar a inclusão.

Portela (2014, p. 64) explica que o liberalismo é a ideologia responsável por difundir a noção de normalidade como elemento fundante da educação escolar, mas o faz numa relação de equivalência com a noção de igualdade. Ao fazê-lo acaba por transpor para a noção de igualdade a concepção de homogeneidade, de padrão e de norma. Assim, o liberalismo faz circular no contexto da educação escolar a crença de que os alunos precisam ser tratados de forma homogênea ou segundo a norma. Como se vê, este é um procedimento que tem por consequência reafirmar a exclusão na medida em que assenta na norma a ação pedagógica.

Outro ponto de vista é o apontado por Carvalho (2010, p. 16). Para a autora, há hoje um procedimento de pôr em oposição educação regular e educação especial, contribuindo perigosamente para um binarismo no campo da educação que produz ilusões sobre os sujeitos da educação e suas necessidades. Nas palavras dela, vivemos hoje "uma verdadeira revolução conceitual, contrapondo termos, construindo diferentes práticas discursivas que sustentam 
a ilusão da igualdade entre as pessoas, ao mesmo tempo em que valorizamos as diferenças individuais e o trabalho na diversidade."

Sobre os marcos internacionais, Magalhães (2011) afirma que estes defendem a perspectiva da educação inclusiva e a compreensão da escola como espaço democrático que deve garantir a aprendizagem de todas as crianças. Libâneo (2012) aborda o tema em outra perspectiva e aponta influências perversas que sustentam duas concepções de escolas Brasil:

[...] o dualismo da escola brasileira em que, num extremo, estaria a escola assentada no conhecimento, na aprendizagem e nas tecnologias, voltada aos filhos dos ricos, e, em outro, a escola do acolhimento social, da integração social, voltada aos pobres e dedicada, primordialmente, a missões sociais de assistência e apoio às crianças. (LIBÂNEO, 2012, p. 16).

Este autor se posiciona criticamente acerca dos marcos internacionais alicerçados pelo comando do Banco Mundial. Ele afirma que esse dualismo perverso que cresce no cenário da educação brasileira é fruto do movimento Educação para Todos, cujo marco é a Conferência Mundial sobre Educação para Todos. Libâneo (2012, p. 18) nos diz que os países signatários, ao acessarem o documento, fizeram diferentes interpretações e usos, às vezes adequando a efetivação da política às exigências do Banco Mundial. Difundiu-se amplamente uma visão que ele denomina encolhida, através da qual se disseminou a ideia de necessidades mínimas de aprendizagem a serem garantidas pelos Estados nacionais; uma interpretação que, segundo o autor, pode levar a negação do direito universal à educação.

Em geral, estudos brasileiros como os de Canan (2016), Breitenbach, Honnef e Costas (2016), Fonseca (2003) e Souza (2005) apontam que os marcos internacionais influenciam os caminhos das políticas públicas educacionais no Brasil e que apesar de proporcionarem aspectos positivos, como a defesa de que todas as crianças devem aprender juntas, efetivamente, as práticas apresentam-se carregadas de contradições, como é o caso da implantação de avaliações nacionais padronizadas.

Canan (2016, p. 73), ao discutir a influência dos organismos internacionais nas políticas educacionais, aprofunda críticas à educação para todos no Brasil. A autora afirma que, a partir dos anos 1980, o Banco Mundial expande suas estratégias, não somente no campo das políticas socias, mas também no das políticas educacionais, especificamente no que concerne ao financiamento, assessoramento e planejamento. E ainda que "os organismos internacionais têm sido determinantes 
de nossas políticas públicas em troca de empréstimos para sua implementação". E, nessa lógica, é evidente que os interesses atendidos são os da elite dominante.

Breitenbach, Honnef e Costas (2016, p. 362) apresentam um estudo acerca das implicações das traduções e interpretações da Declaração de Salamanca no Brasil, analisando a versão publicada em 1994 e a versão disponibilizada atualmente no site do Ministério da Educação. Segundo as autoras,

(...) a primeira versão encerrava um caráter semântico ampliado, no que tange o público da educação inclusiva, ou seja, a educação para todos e a escola comum como responsável maior por esta. De modo diferente, a versão da Declaração de Salamanca, disponível hoje na internet, alia a educação inclusiva à Educação Especial, isto é, a educação inclusiva é pontuada como "tarefa" quase exclusiva da e para a Educação Especial e seu público-alvo. (grifos do autor)

Neste estudo, as autoras se aliam a outros pesquisadores no sentido de alertar para o que efetivamente ambicionam os organismos internacionais, como o Banco Mundial. Por exemplo, ao disseminar a ideia de educação universal baseada numa cesta mínima de direitos que fomenta a noção de uma educação de integração social em oposição a uma educação assentada no conhecimento, este organismo está a influenciar nossas reformas educacionais e, nem sempre, essas permitem a efetivação do direito à educação sem nenhum tipo de discriminação. Evidenciase que o fomento das agências internacionais favorece medidas compensatórias, e mais ainda que as verdadeiras intenções e ideologias se camuflam em meio às medidas disseminadas de educação para todos. Contudo, tais evidências não negam a importância destes marcos na construção dos regramentos legais no cenário brasileiro.

Com isto pretende-se demarcar que este estudo tende a assumir uma postura lúcida, que deseja escapar da alienação apontada por Santos (2011, p.226), quando afirma que "seja o que for que dissermos hoje sobre a cegueira dos outros será provavelmente visto no futuro como sinal da nossa própria cegueira". Assim, ao discutirmos os marcos internacionais, não o fazemos com ingenuidade, mas nos esforçamos por apontar o que há de interferência no campo da educação inclusiva no Brasil.

Da Conferência Mundial de Educação para Todos (UNESCO, 1990) nasceu a Declaração Mundial de Educação para Todos: plano de ação para satisfazer as necessidades básicas da aprendizagem, a qual estabelece princípios e diretrizes orientadoras de reformas educacionais

P/ulais Salvador, v. 3, n.3, p. 12-37, set./dez. 2018 
e indica que os sistemas devem garantir a satisfação das necessidades básicas de aprendizagem, a universalização de acesso à educação e a organização de um ambiente apropriado para a aprendizagem.

A Declaração de Nova Delhi (UNESCO, 1993) reitera o compromisso dos nove países, entre estes, o Brasil, em buscar com determinação as metas definidas pela Conferência Mundial sobre Educação para Todos, eliminando as disparidades do acesso à educação e afirmando que esta não será negada a uma só criança. Já a Conferência Mundial sobre Necessidades Educacionais Especiais que aconteceu em Salamanca (UNESCO, 1994) traz um ordenamento de ações que preconizam os encaminhamentos educativos com ênfase na educação inclusiva, apresentados no documento nomeado Declaração de Salamanca. Enquanto o Fórum Mundial sobre Educação que aconteceu em Dakar, em abril de 2000 (UNESCO, 2000) teve como fim avaliar o cumprimento das metas dez anos após a Conferência Mundial sobre Educação para Todos e reafirmar os compromissos nela postos.

A Convenção Internacional sobre os Direitos das Pessoas com Deficiência, assinada em Nova York em 30 de março de 2007 (ONU, 2007), traz impacto ao ordenamento jurídico brasileiro em forma de Emenda Constitucional, através do Decreto n ${ }^{\circ} 6.949$, de 25 de agosto de 2009. Na legislação brasileira, a convenção (BRASIL, 2009a) traz entre seus princípios: o respeito pela dignidade humana e autonomia individual; a não-discriminação; a plena e efetiva participação e inclusão na sociedade; o respeito pela diferença e diversidade humana; o respeito pelo desenvolvimento das capacidades das crianças com deficiência. Esta convenção demarca nova concepção acerca da capacidade dos sujeitos com deficiência.

\section{Ambiguidades e Hibridismo Conceituais da Educação Especial e da Educação Inclusiva}

Pode-se dizer que as políticas educacionais no Brasil se constituíram sob forte influência das conferências internacionais orientadas pela UNESCO, principalmente, ao trabalhar o princípio da universalização da educação básica. No caso da educação inclusiva, o marco legal é a Política Nacional de Educação Especial na Perspectiva da Educação Inclusiva, implantada pelo MEC em janeiro de 2008.

O Documento Política Nacional de Educação Especial na Perspectiva da Educação Inclusiva (BRASIL, 2008) está estruturado em seis seções. Na seção Apresentação, o texto contextualiza a política no movimento da educação inclusiva e define: 
A educação inclusiva constitui um paradigma educacional fundamentado na concepção de direitos humanos, que conjuga igualdade e diferença como valores indissociáveis, e que avança em relação à ideia de equidade formal ao contextualizar as circunstâncias históricas da produção da exclusão dentro e fora da escola. (BRASIL, 2008, p.5)

Nota-se, no conceito de equidade, o compromisso da política com a inclusão, como caminho possível para a construção de uma escola capaz de alcançar a todos. A educação inclusiva, definida enquanto paradigma, propõe "uma mudança estrutural e cultural da escola para que todos os alunos tenham suas especificidades atendidas". (BRASIL, 2008, p.5)

Na segunda seção, o Documento faz uma retrospectiva histórica e apresenta os marcos normativos, desde a época do império, quando o atendimento às pessoas com deficiência se restringia a duas instituições: o Imperial Instituto dos Meninos Cegos, criado em 1854, e o Instituto dos Surdos Mudos, fundado em 1857, chegando até ao Decreto no 6.094 de 2007 que estabelece as diretrizes do Compromisso Todos pela Educação. (BRASIL, 2008)

A terceira seção tem a função de apresentar dados acerca do diagnóstico da educação especial no Brasil, a partir do censo escolar, chamando atenção para a evolução expressa do número de matrículas de educação especial em escolas regulares. Quanto aos objetivos da política, estes são apresentados na quarta parte do documento:

Assegurar a inclusão escolar de alunos com deficiência, transtornos globais do desenvolvimento e altas habilidades/superdotação, orientando os sistemas de ensino para garantir: acesso ao ensino regular, com participação, aprendizagem e continuidade nos níveis mais elevados do ensino; transversalidade da modalidade de educação especial desde a educação infantil até a educação superior; oferta do atendimento educacional especializado; formação de professores para o atendimento educacional especializado e demais profissionais da educação para a inclusão; participação da família e da comunidade; acessibilidade arquitetônica, nos transportes, nos mobiliários, nas comunicações e informação; e articulação intersetorial na implementação das políticas públicas. (BRASIL, 2008, p. 14) 
No Documento, a educação inclusiva é definida como proposta educacional que reconhece e garante o direito de todos os alunos de compartilhar um mesmo espaço escolar, sem discriminações de qualquer natureza. Ela deve ser promotora da igualdade e valorizar as diferenças na organização do currículo. Este último deve favorecer a aprendizagem e atender às necessidades de todos os alunos, sem discriminação. Já a educação especial é definida como campo de conhecimento e modalidade educacional que transversaliza o ensino nos diferentes níveis, etapas e demais modalidades. (BRASIL, 2008)

Além disso, na Política, evidencia-se o uso do termo necessidades educacionais especiais, o qual nos remete à Declaração de Salamanca, versão difundida no Brasil. Dessa forma, restringese a garantia deste atendimento a um grupo específico, diferentemente da proposição constante na $1^{\text {a }}$ versão da Declaração de Salamanca, conforme apontam Breitenbach; Honnef e Costas (2016, p. 370).

Assim sendo, na elaboração das políticas públicas para educação especial no Brasil, inclui-se e exclui-se e, conforme se inclui, excluise duplamente. Muitos dos alunos com necessidades educativas especiais, incluídos/elencados na Declaração de Salamanca, não foram contemplados pelas políticas de educação especial [...].

Este é o assunto tratado na quinta parte do Documento, a saber, alunos atendidos pela educação especial. Categorizam-se: alunos com deficiência, transtornos globais de desenvolvimento e altas habilidades/superdotação. Uma política de inclusão na educação ao circunscrever seu público-alvo, apenas, na tradição do normal e do patológico incorre num procedimento reducionista e alia-se a lógica da medicalização ${ }^{5}$ da educação e da infância.

Um dos efeitos desse procedimento foi a necessidade de instituir-se a emissão de laudos diagnósticos para a garantia do Atendimento Educacional Especializado (AEE). Este movimento ao pretender orientar a inclusão está a reintroduzir a hegemonia do discurso biomédico para os sujeitos marcados pela diferença. Segundo Taño (2017, p.106-107) “... se mantém presente e forte

\footnotetext{
${ }^{5}$ Sobre esse tema ver Collares, Moysés e Ribeiro (2013). As organizadoras da obra Novas capturas, antigos diagnósticos na era dos transtornos reúnem artigos os quais discutem a lógica da medicalização que avança assustadoramente sobre as diversas esferas da vida, ocultando desigualdades e individualizando-as ao plano biológico do sujeito. Essa lógica tem alcançado a educação e colocado os problemas educacionais na conta do "sujeito que não aprende" por suas próprias questões.
} 
a tradição histórica e com raiz bastante higienista, de se legar ao aparato médico e da saúde a outorga para os processos de inclusão escolar das crianças e adolescentes".

É nesta perspectiva que não se pode deixar de indagar sobre as práticas educacionais dirigidas aos sujeitos que não aprendem no tempo e no rito estabelecido pela educação escolar, fazendo-os responsáveis pelo próprio fracasso. O que nos faz interrogar a concepção de educação para todos, muitas vezes propagada, sem efetivo e amplo debate com diferentes grupos sociais sobre os caminhos possíveis para sua efetivação como política pública.

Seguindo a classificação, o documento da Política complementa: "Nestes casos e outros, que implicam em transtornos funcionais específicos, a educação especial atua de forma articulada com o ensino comum, orientando para o atendimento às necessidades educacionais especiais desses alunos". (BRASIL, 2008, p.15) Nesta citação, observa-se que a Política reconhece a ocorrência de outros casos de transtornos funcionais específicos, contudo não indica ou estabelece diretrizes de ação para estes. Isto nos leva a pensar que, embora o documento deixe brechas para a educação inclusiva atender crianças com necessidades diferentes daquelas descritas para o público alvo da educação especial, a Política não aponta caminhos para sua efetivação.

Esta imprecisão pode induzir equívocos nas ações de planejamento no âmbito da gestão educacional; entre esses, restringir a oferta de atendimento educacional especializado as três categorias especificadas como público-alvo da educação especial: alunos com deficiência, transtornos globais de desenvolvimento e altas habilidades/superdotação. Como se sabe a Política quer garantir sua efetivação sem restringir o seu alcance a um público-alvo. A Política quer promover o acesso de todas as pessoas à educação e produzir as condições de aprendizagem a todos os alunos, e prezar pela qualidade da educação ofertada.

Se seguirmos a estrutura do documento, a sexta parte apresenta as diretrizes da Política. Nesta reafirma-se a posição da educação especial enquanto modalidade educacional, como também se introduz o funcionamento e a organização do Atendimento Educacional Especializado, cujas diretrizes operacionais constam na Resolução Conselho Nacional da Educação/Câmara de Educação Básica (CNE/CEB) nº 4 de 2009.

Esta breve análise do documento sugere que fiquemos atentos para as ambiguidades no uso dos conceitos de educação inclusiva e educação especial, o que evidentemente aponta para consequências no plano da gestão da educação, em especial no planejamento, ação que deve expressar os mecanismos de inclusão a serem operados pelos sistemas de ensino.

P/Ullais Salvador, v. 3, n.3 , p. 12-37, set./dez. 2018 


\section{Descaminhos da inclusão para a população infantojuvenil usuária de saúde mental}

Um segmento populacional que tem importância para a educação inclusiva é o de crianças e adolescentes usuárias de saúde mental. Porém, este público não encontra identidade com o público alvo da educação especial. Por este motivo cabe perguntar como o setor educação conduz a inclusão educacional dessa população?

Pode-se dizer que este é um dos descaminhos da educação inclusiva no Brasil, aquele que circunscreve um público alvo bastante restrito para a educação especial. Pessoas que apresentam outras necessidades ou condições específicas que interferem ou dificultam o processo de aprendizagem acabam por ser secundarizados ou mesmo conduzidos a uma posição de exclusão do processo educacional.

De acordo com a Resolução $\mathrm{n}^{\circ} 4$ de 2009 (BRASIL, 2009b) que trata do atendimento educacional especializado, a efetivação da inclusão escolar exige, entre outras ações, a construção de redes intersetoriais. Neste caso se pode supor que os regramentos legais no Brasil estão a nos orientar a construir ações entre os setores educação e saúde para efetivar a inclusão na educação. Os registros históricos mostram que educação e saúde estiveram juntas, mesmo antes da dissociação entre deficiência e loucura ${ }^{6}$, quando a aliança médico-pedagógica trabalhava na classificação e diagnóstico dos diferentes.

Segundo Costa (1976), o sistema produtivo emergente na revolução industrial transformou as relações sociais. Aqueles que não pudesse participar ativamente para a lógica de produção de lucro deveriam ser retirados do convívio social. Assim, crianças abandonadas, idosos, deficientes, mendigos e loucos passaram a ocupar verdadeiros depósitos humanos.

Conforme Alves et al. (2009, p. 86), a representação da loucura no medievo correspondia “... a expressão das forças da natureza ou algo da ordem do não-humano. Era exaltada, num misto de terror e atração. [...] era tida como possessão por espíritos maus". O que se vê, nesta narrativa, é o que Scliar (2007, p.30) denomina de fundamentos mágico-religiosos, aqueles que constroem

\footnotetext{
${ }^{6}$ Utilizamos o termo loucura, na perspectiva adotada por Taño (2017, p. 200): “[...] a loucura e o sofrimento psíquico são entendidos como processos sociais/relacionais que se efetuam a partir dos encontros coexistindo com os modos com que determinada sociedade enxerga/acolhe e produz tais experiências".
} 
a representação do que vem a ser sanidade e loucura assentado "na ação de forças alheias ao organismo".

No caso de crianças com deficiência, Ferreira e Guimarães $(2003$, p. 53, 56) referem que a prática de abandonar essas crianças a própria sorte encontrava naturalização na vida social. Conforme os autores “... não parecia cruel abandonar tais crianças, [...] estavam os mortais obedecendo aos desejos e imposições dos deuses”. Se seguirmos a interpretação de Scliar (2007, p. 32), o que está assentado nesta narrativa é uma concepção mitológica para justificar as práticas sociais que levavam crianças com deficiência a óbito.

Como se vê o diálogo das sociedades humanas com a loucura, a deficiência e a diferença se assentam em concepções que dizem de um tempo histórico, suas crenças e de práticas socioculturais consensuadas. Ocorre que esses modos de operar implicam em consequências. Ferreira e Guimarães (2003) afirmam que a concepção mitológica trouxe para a deficiência o fardo da impotência e da imperfeição tendo por referência um ideal divino. Além disso, a concepção mágico-religiosa fortaleceu superstições que disseminavam a ideia de que os sujeitos com deficiência eram habitados por maus espíritos.

Para Machado(2005), a obra de Michel Foucault História da loucura nos mostra que a loucura é enunciada no terreno das experiências negativas. E, por decorrência, a deficiência e a diferença são arroladas como experiências cujo estatuto corresponde ao da loucura. Portanto, a pessoa com deficiência, assim como o louco, sofre com segregação, enclausuramento e discriminação. Esses procedimentos foram acionados através de dispositivos técnicos de controle como os asilos de alienados, cuja função consistia em efetuar a afirmação da loucura, da deficiência e da diferença como experiências disfuncionais para a ordem social. (SERRA, 1979; MACHADO, 2005)

Conforme Machado (2005, p. 28 e 29), a partir da obra de Michel Foucault, pode-se distinguir três momentos deste processo de captura da loucura como experiência a ser controlada. Uma captura é moral, outra é racional e, a mais recente, refere-se à noção de doença mental.

A captura da loucura pela dimensão moral se passa no século XV, por exemplo, quando esta é associada à ideia de experiências de "miragem, sonho, ilusão", como o que se vê nas aventuras do personagem Dom Quixote de la Mancha de Miguel de Cervantes. Já o século XVII, a anuncia desclassificando-a como experiência que se opõe à razão. Para a época clássica "a loucura se torna condição de impossibilidade do pensamento. Se eu penso não posso ser louco, se sou louco não posso pensar". A modernidade, por sua vez, faz da loucura doença mental e experiência de interioridade. Conforme Machado (2005, p. 30), desde o século XIX, "a alienação

P/ulais Salvador, v. 3, n.3, p. 12-37, set./dez. 2018 
mental não é mais [...] uma ausência de razão, mas um antagonismo [...] A loucura, agora doença mental, diz respeito à alma humana, penetra em sua interioridade [...] o homem, em estado de loucura perde sua verdade, sua essência...”.

Quanto à concepção de loucura na infância, SILVA et al. (2006) afirmam que seu surgimento foi tardio. Durante quase todo o século XIX, vigorou a certeza de que quem enlouquecia era o adulto, ou, no máximo, o adolescente. Ainda assim, o que se sabia sobre a loucura é que esta não remontava aos acontecimentos da infância. Partia-se do princípio de que "a doença mental era uma predisposição inata, um choque recente ou ambos. Ninguém ficava louco por sua infância e muito menos no seu tempo de infância". (SILVA et al. 2006, p.7) Para os autores esse é por esse motivo que se diz que a criança anormal surge, não da infância louca, mas, sim, do idiota.

Silva et al. (2006) nos diz que no século XIX a discriminação da criança com deficiência passa a ser cientificamente legitimada pelos estudos de Edouard Séguin ${ }^{7}$ (1846), quando este propõe a noção de fases no desenvolvimento. No caso da criança normal ela ultrapassaria a fase idiota e no caso da criança anormal ela estagnaria na fase idiota. Silva, et al (2006) apontam a importância as contribuições de Edouard Séguin para o percurso da psiquiatria, bem como para a aliança dos saberes do campo psi com a pedagogia.

Em nosso país, esta aliança parece datar de 1903, com a separação institucional das crianças anormais pela criação do primeiro pavilhão de crianças no interior do Hospício Nacional, o Pavilhão Escola Bourneville. Antes disso, não se havia destinado especial atenção à figura das anormalidades infantis neste país. Os mecanismos segregatórios do século XIX tinham como ideais as normas impostas pela medicina higienista. (SILVA, et al., 2006, p.2), 1988).

De acordo com Silva et al. (2006), a partir das campanhas de profilaxia nas escolas, em 1908, multiplicaram-se no Brasil especialistas da correção, do tratamento e da prevenção. Neste ano foi criada em São Paulo a primeira inspeção médico-escolar com o objetivo de realizar a chamada profilaxia ativa, quando a escola passa a disseminar noções de higiene para a família e,

\footnotetext{
${ }^{7}$ Fundador da primeira escola para tratamento de crianças e jovens com deficiência intelectual e autor do livro Traitement moral, hygiène et éducation des idiots et des autres enfants arriérés (1846). Seu método era baseado no funcionamento da inteligência e considerava os aspectos físicos e suas funções, os aspectos psicológicos, os interesses e as experiências dos sujeitos.
} 
consequentemente, para toda a sociedade. Em 1910 fundou-se no Rio Janeiro um serviço com o mesmo objetivo, o de divulgar as ideias da inspeção médico-escolar.

Os autores afirmam que esse foi um contexto no qual os saberes médico-pedagógicos disseminaram classificações, diagnósticos, prognósticos, recomendações higiênicas e pedagógicas. Mesmo após o término dos serviços de inspeção médico-escolar, a escola continuou sendo vista como palco principal da procura pelos possíveis anormais, entretanto o principal protagonista desta procura não é mais o médico, mas o professor, que passa então a emitir as primeiras impressões diagnósticas, no lugar da inspeção médica. São os professores que passam a classificar as crianças como anormais ou incapazes. (SILVA et al, 2006)

Nesse período, segundo Silva et al. (2006), o máximo que se viu enquanto especificidade da infância, foi o entendimento de que a criança ao conviver com o adulto, passa a correr o risco de se tornar um adulto degenerado. A partir daí houve a separação dos adultos das crianças, que até então dividiam os mesmos espaços nos hospícios.

Segundo Couto (2012), somente após 2001 se presencia rudimentos no delineamento da política de saúde mental para a infância e adolescência no Brasil. A autora demarca que dois movimentos precedentes, de maior amplitude, foram decisivos nesta conjuntura e que ambos corroboraram para o marco da história desta política, a nova concepção de criança e adolescente:

O primeiro, a Convenção Internacional sobre os Direitos da Criança, realizada pela Organização das Nações Unidas (ONU) em 1989, da qual o Brasil foi signatário, que sintetizou um novo paradigma para interpretar a situação da infância na sociedade, ao afirmar a criança como sujeito e cidadão de plenos direitos (ONU, 1989). O segundo, a promulgação, no Brasil, do Estatuto da Criança e do Adolescente (ECA), em 1990 (BRASIL, 1990), que estabeleceu direitos de cidadania para crianças e adolescentes e alterou a condição jurídica anterior de 'menores' para a de sujeitos de direitos, substituindo a doutrina da situação irregular pela da proteção integral, como marco orientador das novas políticas a serem dirigidas a eles. (COUTO, 2012, p.7, grifos do autor)

Trata-se de movimentos mais amplos ao contexto do setor saúde, com implicação direta nos rumos tomados pelas políticas infantojuvenis nos setores da assistência social, justiça e direitos humanos. Dessa forma, os dois marcos corroboraram para o desenvolvimento de políticas de saúde mental para a infância e adolescência no Brasil.

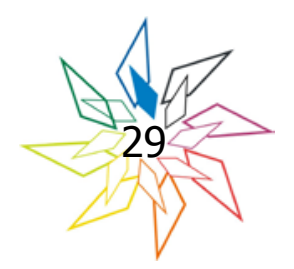


Importante destacar que a partir da Lei 8.069, de 13 de julho de 1990 que promulga o ECA, o Estado passa a assumir a proteção integral da criança e do adolescente e deixa a função de tutela, "conferindo a garantia legal a um conjunto de direitos para todas as crianças e jovens brasileiros, sem distinção". (COUTO, 2012, p. 07)

No caso brasileiro pode-se considerar que os movimentos da Reforma Sanitária e da Reforma Psiquiátrica contribuíram para problematizar e por em xeque o modelo de assistência centrado na psiquiatria manicomial, e baseado na segregação, no isolamento e na tutela das pessoas com deficiência e/ou sofrimento psíquico grave. (BRASIL, 2005b) A culminância desses movimentos sociais encontrou formalização institucional na $8^{\text {a }}$ Conferência Nacional de Saúde realizada em Brasília no ano de 1986 (BRASIL, 1986) e em 1988 com a promulgação da Constituição Federal que dedica um capítulo para as garantias e direitos relativos à saúde. (BRASIL, 1988)

É assim que Couto (2012) destaca a Lei da Saúde Mental, Lei 10.216/2001 e a realização da III Conferência Nacional de Saúde Mental (CNSM), também em 2001, para a construção da política de saúde mental para a infância e adolescência. Conforme a autora

Com a Lei, a saúde mental passou a constituir uma política de Estado e não apenas um programa de governo, ancorada na defesa dos direitos de cidadania dos pacientes mentais. A inflexão comunitária das ações fez emergirem novas questões para a saúde mental - só visíveis a partir do território -, como a da necessária inclusão no campo do cuidado dos problemas mentais em crianças e adolescentes [...] (COUTO, 2012, p. 6)

Com a promulgação dessa Lei nascem os Centros de Atenção Psicossocial (CAPS), regulamentados pela Portaria $n^{0}$ 336/GM, de 19 de fevereiro de 2002, com o objetivo de substituir os hospitais psiquiátricos e compor a rede do Sistema Único de Saúde (SUS). Dentre suas modalidades encontra-se o Centro de Atenção Psicossocial para a Infância e Adolescência (CAPS i), serviço aberto com atendimento diário destinado a crianças e adolescentes com agravos psíquicos impossibilitantes de manter ou estabelecer laços sociais com autonomia. $\mathrm{O}$ trabalho do CAPS i ancora-se, entre outros princípios, na articulação intersetorial.

O princípio da intersetorialidade, marcado na Política Nacional de Educação Especial na Perspectiva da Educação Inclusiva, ao citar a "articulação intersetorial na implementação das políticas públicas" (BRASIL, 2008, p.14), também é defendido no guia Caminhos para uma política de saúde mental infanto-juvenil (BRASIL, 2005a), quando orienta a ampliação do cuidado, não somente no setor saúde, mas também no setor educação. 
A dimensão da instersetorialidade é pautada, também, na IV Conferência Nacional de Saúde Mental - Intersetorial (CNSM-I), corrida em 2010, ao defender as interfaces diversas e recíprocas entre o campo da saúde mental e outros campos como a educação. Seu relatório destaca entre os princípios e diretrizes, o fortalecimento de políticas intersetoriais orientadas para a saúde mental e para a atenção integral à criança e ao adolescente, e, por conseguinte, a consolidação do fundamento intersetorial, em todos os níveis, na organização da rede, principalmente no tocante à educação, assistência social e justiça. (BRASIL, 2010)

Injosa (2001, p.103) conceitua intersetorialidade como "a articulação de saberes e experiências para a solução sinérgica de problemas complexos". A autora fala da tessitura da vida como uma complexidade, pois as necessidades de um sujeito ou de um grupo não consiste como fato isolado, essas se apresentam integradas e interligadas. Dessa forma, "coisas separadas ou itens isolados não dão conta de promover qualidade de vida, de fomentar o desenvolvimento, de superar a exclusão social."

Cabe-nos refletir sobre a fragmentação e sobreposição de saberes enraizados nos especialíssimos dos dois setores - educação e saúde. Por vezes a responsabilização pelo trabalho com crianças e adolescentes com deficiência é atribuída apenas aos professores do AEE, o que pode indicar que a escola não os reconhece efetivamente enquanto sujeitos de direitos.

Vale realçar a premissa da qual partem as duas políticas, educação especial e saúde mental infantojuvenil: o reconhecimento da criança e do adolescente como sujeitos de direitos e de responsabilidades. O eixo central é o protagonismo da criança e do adolescente com voz própria, sem que outras vozes falem deles ou por eles. (BRASIL, 2005a; BRASIL, 2008)

Outro princípio firmado na Política Nacional de Educação Especial na Perspectiva da Educação Inclusiva trata da participação da família e da comunidade (BRASIL, 2008). Preceito que dialoga com o que é posto na política de saúde mental infantojuvenil (BRASIL, 2005a), ao recomendar o fortalecimento das redes de apoio comunitárias e familiares e defender que a criança, o adolescente e sua família devem ser protagonistas da emancipação.

Suscitamos, portanto, que o diálogo entre os dois setores, tanto no campo da gestão, como na assistência, efetivará as conexões postas nas políticas, sejam as definidas claramente, sejam as observadas timidamente nas brechas, a partir de olhares mais aprofundados. Faz-se necessário pactuar ações efetivas entre os setores, a começar nos planos decenais de educação, para assim caminharmos para a efetividade da política de educação especial.

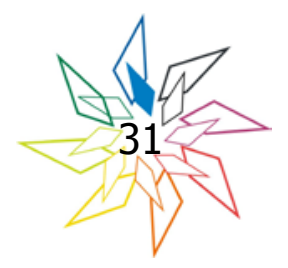




\section{Conclusões}

Este estudo, ao analisar as políticas em tela, buscou associar-se aqueles movimentos que visam superar os descaminhos nos quais a inclusão foi lançada no cenário brasileiro. Apresentouse indícios de que as políticas públicas para a educação inclusiva e para a educação especial no Brasil são construídas a partir de interpretações, por vezes redutoras, ligadas a interesses ambíguos dentro de uma conjuntura política, como é o caso da interpretação da Declaração de Salamanca.

Considerou-se, também, que os marcos internacionais indicam os caminhos para o delineamento dos regramentos legais da educação especial em nosso país, ora sugerindo possibilidades de avanços, como é o caso da universalização da educação básica, ora atrelandoos a práticas e conceitos oriundos de tradições conflitantes, como é o caso da noção de norma.

Evidencia-se a importância da Política Nacional de Educação Especial na Perspectiva da Educação Inclusiva para o efetivo atendimento à garantia do direito a todos os sujeitos. Mas efetivar práticas inclusivas na educação significa também atender a população infantojuvenil usuária de saúde mental, além do públicoalvo já contemplado na Política - alunos com deficiência, transtornos globais de desenvolvimento e altas habilidades/superdotação.

Para se efetivar a inclusão de crianças e adolescentes vinculados à educação básica e suas diferentes necessidades de aprendizagem, o texto aponta para o princípio da intersetorialidade, preconizado nas políticas de educação especial e de saúde mental. A operacionalização desse princípio exige proposição de ações nos planos de educação e saúde, de modo que a gestão governamental assuma a efetivação da inclusão como direito de todos.

É importante referir que o regramento legal, por si só, não transforma a realidade das instituições, dos coletivos e dos sujeitos. Contudo, enquanto resultado de embates e forças de interesses de grupos diversos, ao se constituir como política pública, assume o caráter orientador para as práticas sociais.

\section{REFERÊNCIAS}

ALVES, Carlos Frederico de Oliveira. et al. Uma breve história da reforma psiquiátrica. Neurobiologia. 72 (1), jan. mar., 2009. 
BRASIL. Relatório Final da $8^{\text {a }}$ Conferência Nacional de Saúde. 17 a 21 de março de 1986. Disponível em: <http://bvsms.saude.gov.br/bvs/publicacoes/8_conferencia_nacional_saude_ relatorio_final.pdf.> Acesso em 10 jul. 2018.

. Constituição Federal. Brasília, 1988.

. Lei $\mathbf{n}^{\mathbf{0}}$ 8.069/90. Dispõe sobre o Estatuto da Criança e do Adolescente e dá outras providências. Brasília, DF, 1990.

. Lei $\mathbf{n}^{\mathbf{0}}$ 9.394/1996. Estabelece as diretrizes e bases da educação nacional. Brasília, 1996.

Lei 10.216/2001. Dispõe sobre a proteção e os direitos das pessoas portadoras de transtornos mentais e redireciona o modelo assistencial em saúde mental. Brasília: Ministério da Saúde, 2001.

. MINISTÉRIO DA EDUCAÇÃO. Educação inclusiva: A fundamentação filosófica. Brasília: Secretaria de Educação Especial, 2004. V.1.

. MINISTÉRIO DA SAUUDE. Caminhos para uma política de saúde mental infantojuvenil. Secretara de Atenção à Saúde. Brasília: Editora do Ministério da Saúde, 2005 (a).

MINISTÉRIO DA SAÚDE. Reforma psiquiátrica e política de saúde mental no Brasil. Secretara de Atenção à Saúde. Coordenação Geral de Saúde Mental. Documento apresentado à Conferência Regional de Reforma dos Serviços de Saúde Mental: 15 anos depois de Caracas. OPAS. Brasília: 2005 (b).

MINISTÉRIO DA EDUCAÇÃO. SECRETARIA DE EDUCAÇÃO ESPECIAL. Política Nacional de Educação Especial na Perspectiva da Educação Inclusiva. Brasília, DF, jan. 2008. Disponível em: <http://portal.mec.gov.br/arquivos/pdf/politicaeducespecial.pdf.> Acesso em: 10 jan. 2018.

Decreto $n^{0}$ 6.949, de 25 de agosto de 2009. Promulga a Convenção Internacional sobre os Direitos das Pessoas com Deficiência e seu Protocolo Facultativo, assinados em Nova York, em 30 de março de 2007. Brasília, 2009 (a) 
.Resolução CNE/CEB No 4, de 02 de outubro de 2009. Institui Diretrizes Operacionais para o Atendimento Educacional Especializado na Educação Básica, modalidade Educação Especial. Brasília: Ministério da Educação, 2009 (b).

. MINISTÉRIO DA SAÚDE/ CONSELHO NACIONAL DE SAÚDE. Relatório Final da IV Conferência Nacional de Saúde Mental - Intersetorial. Brasília: CNS/MS, 2010.

Lei $N^{0}$ 13.005, de 25 de junho de 2014. Aprova o Plano Nacional de Educação. Brasília: Ministério da educação, 2014.

BREITENBACH, Fabiane Vanessa; HONNEF, Cláucia; COSTAS, Fabiane Adela Tonetto. Educação inclusiva: as implicações das traduções e das interpretações da Declaração de Salamanca no Brasil. Ensaio: aval. pol. públ. Educ., Rio de Janeiro, v.24, n. 90, p. 359-379, abr./ jun. 2016.

CANAN, Silvia Regina. Influência dos organismos internacionais nas políticas educacionais: só há intervenção quando há consentimento? $1^{\text {a }}$ Ed. Campinas, SP: Mercado de Letras, 2016.

CARVALHO, Rosita Edler. Educação inclusiva: com os pingos nos “is”. Porto Alegre: Mediação, 2010

COLLARES, Cecília de Azevedo Lima; MOYSÉS, Maria Aparecida Affonso; RIBEIRO, Mônica Cintrão França. Novas capturas, antigos diagnósticos na era dos transtornos: Memórias do II Seminpario Internacional Educação Medicalizada... $1^{\text {a }}$ ed. Campinas, SP: Mercado de Letras, 2013.

COSTA, Juradir Freire. História da Psiquiatria no Brasil. Rio de Janeiro: Documentário Editora, 1976.

COUTO, Maria Cristina Ventura. Política de Saúde Mental para crianças e adolescentes: especificidades e desafios da experiência brasileira (2001-2010). Tese de doutorado. Instituto de Psiquiatria da Universidade Federal do Rio de Janeiro. RJ: 2012.

FERREIRA, Maria Elisa Caputo; GUIMARÃES, Marly. Educação inclusiva. Rio de Janeiro: DP\&A, 2003.

FONSECA, Marília. O Banco Mundial e a gestão da educação brasileira. In: OLIVEIRA, D. A. (Org.). Gestão democrática da educação: desafios e conflitos. $5^{\mathrm{a}}$ ed. Petrópolis: Vozes, 2003. 
INOJOSA, Rose Marie. Sinergia em política e serviços públicos: desenvolvimento social com intersetorialidade. Cadernos FUNDAP. São Paulo, n.22, p. 102-110, 2001.

JANNUZZI, Gilberta Sampaio de Martino. A educação do deficiente no Brasil: dos primórdios ao início do século XXI. Campinas: Autores Associados, 2004.

LAKATOS, Eva Maria; MARCONI, Marina de Andrade. Fundamentos de metodologia científica. $5^{\text {a }}$ ed. São Paulo: Atlas, 2003.

LIBÂNEO, José Carlos. O dualismo perverso da escola pública brasileira: escola do conhecimento para os ricos, escola do acolhimento social para os pobres. Educação e Pesquisa, São Paulo, 2012, vol.38, n.1, p.1328.

LÜDKE, Menga; ANDRÉ, Marli E.D. Pesquisa em Educação: abordagens qualitativas. Rio de Janeiro: E.P.U, 2015.

MACHADO, Roberto. Foucault, a filosofia e a literatura. Rio de Janeiro: Jorge Zahar, 2005

MAGALHÃES, Rita de Cássia Barbosa. Educação inclusiva e escolarização: política e formação docente. Brasília: Liber livro, 2011.

MANTOAN, Maria Teresa Egler. Inclusão Escolar: o que é? por quê? como fazer? São Paulo: Moderna, 2003.

MENDES, Enicéia Gonçalves. A radicalização do debate sobre inclusão escolar no Brasil. Revista Brasileira de Educação, 2006, vol.11, n.33, pp. 387-405.

ORGANIZAÇÃO DAS NAÇÕES UNIDAS. Convenção sobre os Direitos das Pessoas com Deficiência. Aprovada pela Assembleia Geral da ONU em dezembro de 2006. Nova York, 2007. Disponível em: <http://www.bengalalegal.com/onu.php>. Acesso em 10 mai. 2018.

PORTELA, Cláudia Paranhos de Jesus. Convivendo com a deficiência intelectual: percursos de cuidado e educação nas redes parental e social de apoio. Tese de Doutorado. Programa de Pós-Graduação em Educação e Contemporaneidade, Universidade do Estado da Bahia. Salvador, 2014. 
SANCHES, Antonio Carlos Gonsales; OLIVEIRA, Márcia Aparecida Ferreira. Educação Inclusiva e alunos com transtorno mental: um desafia interdisciplinar. Psicologia: Teoria e Pesquisa, Brasília, 2011, vol. 27, n.4, p.411-418.

SANTOS, Boaventura de Souza. A crítica da razão indolente: contra o desperdício da experiência. São Paulo: Cortez, 2011.

SCLIAR, Moacyr. História do conceito de saúde. Physis: Rev. Saúde Coletiva, 2007, vol.17, n.1, pp.29-41. Disponível em:< http://www.scielo.br/pdf/physis/v17n1/v17nla03>. Acesso em 20 jul. 2018.

SERRA, Antônio. A Psiquiatria como discurso político. Rio de Janeiro: Achiamé, 1979.

SILVA, Izaque Miguel da et al . A Aliança Médico-Pedagógica: uma genealogia do Processo de exclusão/demanda. Anais do XIV Encontro Nacional da ABRAPSO. Rio de Janeiro, 2006. Disponível em: <http://www.abrapso.org.br.> Acesso em 17 jan. 2018.

SOUZA, Paulo Renato. A revolução gerenciada: educação no Brasil 1995-2002. São Paulo: Prentice Hall, 2005.

TAÑO, Bruna Lidia. A constituição de ações intersetoriais de atenção às crianças e adolescentes em sofrimento psíquico. Tese de Doutorado. Programa de Pós-Graduação em Ed. Especial do Centro de Educação e Ciências Humanas, Universidade Federal de São Carlos. São Carlos, 2017.

UNESCO. Conferência Mundial sobre Educação para Todos. Jomtien, Tailândia: 1990. Disponível em: $<$ http://unesdoc.unesco.org/images/0008/000862/086291.pdf $>$. Acesso em 05 fev. 2018.

A Declaração de Nova Delhi sobre Educação Para Todos. Nova Delhi, Índia: 1993. Disponível em: <http://unesdoc.unesco.org/images/0013/001393/139393por.pdf > Acesso em 10 mai. 2018.

Declaração de Salamanca sobre princípios, política e práticas na área das necessidades educativas especiais. Salamanca: 1994. Disponível em: <http://unesdoc.unesco. org/images/0013/001393/139394por.pdf> Acesso em: 05 fev. 2018. 
O Marco de Ação de Dakar Educação Para Todos: atendendo nossos Compromissos Coletivos. Dakar: Cúpula Mundial de Educação, 2000. Disponível em: < http://unesdoc.unesco. org/images/0012/001275/127509porb.pdf>. Acesso em: 10 mai. 2018.

VEIGA-NETO, Alfredo; LOPES, Maura Corcini. Inclusão e Governamentalidade. Educ. Soc. Campinas, 2007. Vol 28, n. 100.

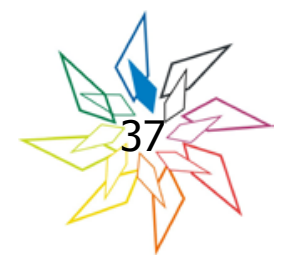

